\title{
International Conference on Recent Advances in Neurotraumatology
}

Taipei, Taiwan, November 20-23, 1999

Sponsored by the Neurotraumatology Committee of the World Federation of Neurosurgical Societies.

Main topics: Prevention and Control of Neurotrauma; Guidelines of Traumatic Brain Injury, Spinal Cord Injury and Neurorehabilitation.

For details please contact:

Organising Secretariat

Round Table PCO

3F, No. 2, 415 Lane, Kuangfu South Road

Taipei, Taiwan (ROC)

Tel. +8862 275 82602, Fax +886227298638

E-Mailnpco@ms4.hinet.net

\section{KARGER}

Fax +41613061234

E-Mail karger@karger.ch www. karger.com (c) 1999 S. Karger AG, Basel

Accessible online at: http://BioMedNet.com/karger 